Check for updates

Cite this: RSC Adv., 2018, 8, 37842

Received 13th August 2018

Accepted 27th September 2018

DOI: $10.1039 / \mathrm{c} 8 \mathrm{ra06786d}$

rsc.li/rsc-advances

\section{Protective desilication of highly siliceous H-ZSM-5 by sole tetraethylammonium hydroxide for the methanol to propylene (MTP) reaction $\uparrow$}

\begin{abstract}
Yunpeng Zhang, Minggang Li, Enhui Xing, Yibin Luo (D)* and Xingtian Shu
Protective desilication of highly siliceous $\mathrm{H}$-ZSM-5 was effectively realized by dissolution and recrystallization in tetraethylammonium hydroxide (TEAOH) solution. With better balance between dissolution of $\mathrm{OH}^{-}$and recrystallization of $\mathrm{TEA}^{+}$, intracrystalline mesopores could be generated by selective dissolution of Si by the drilling effects of TEAOH on the micropores, and then Si species in the mother liquor near the external surface could be recrystallized into ZSM-5 shell. With a significantly reduced diffusion length provided by the intracrystalline mesopores, TEAOH-treated samples exhibited longer lifetime and higher propylene selectivity than the parent $\mathrm{H}-\mathrm{ZSM}-5$ zeolite. The mediumly-treated T-16 h sample possessed the longest MTP lifetime of $140 \mathrm{~h}, 5.6$ times that of the parent H-ZSM-5 zeolite. Furthermore, the coke content and adsorbed methyl benzene species on the T-16 h sample were heavier than those on the parent H-ZSM-5 sample, which were related to the intracrystalline mesopore structure.
\end{abstract}

\section{Introduction}

Propylene, as the raw material for a wide variety of products such as polypropylene, polyacrylonitrile, isopropyl alcohol, acrolein and acrylic acid, is one of important products in the petrochemical industry. ${ }^{1}$ Propylene was mainly produced from fossil resources via steam cracking and fluid catalytic cracking. ${ }^{2}$ The methanol-to-propylene (MTP) reaction is one of the most important reactions in $\mathrm{C} 1$ chemistry, which has provided an alternative route to fossil-based process for producing propylene..$^{3-5}$ Zeolites with uniform microporous channels, tunable acidity, and high hydrothermal stability such as ZSM-5, ${ }^{6}$ ZSM-11, ${ }^{7}$ ZSM-22, ${ }^{8}$ and $\beta$ zeolites ${ }^{9}$ have been extensively tested for the MTP reaction, among which ZSM-5 has been proven to be the optimum catalyst because of its unique threedimensional pore structure with straight channels $(5.3 \times 5.6$ $\AA)$ and intersecting zigzag channels $(5.1 \times 5.5 \AA) .{ }^{10,11}$ ZSM-5 catalysts had been commercially available for MTP process by Lurgi. ${ }^{12}$

Better propylene selectivity and longer lifetime are two key challenges for the designing of MTP catalysts..$^{13}$ In general, acidity and porosity are the two main factors influencing product selectivity and lifetime. However poor diffusion of coke precursors from active centers could lead to coke deposition to block and cover active sites within channels of ZSM-5. ${ }^{14,15}$ In

Research Institute of Petroleum Processing Sinopec, Xueyuan Road No. 18, Beijing, China. E-mail: luoyibin.ripp@sinopec.com

$\dagger$ Electronic supplementary information (ESI) available: $\mathrm{XRD}, \mathrm{NH}_{3}$-TPD, methanol conversion and products selectivity over TPA-16 h sample in MTP reaction. See DOI: $10.1039 / \mathrm{c} 8 \mathrm{ra06786 \textrm {d }}$ order to overcome the above disadvantages, ZSM-5 with a secondary network of mesopores and micropores was obtained by dealumination or desilication treatment. ${ }^{16}$

As for highly siliceous ZSM-5 zeolite, dealumination has poor efficiency in generating enough mesopores. More importantly, framework Al sites are also removed during dealumination. Therefore, base leaching is a simple but effective in generating adequate mesopores, which differs from dealumination, as silicon, rather than aluminum, is effectively extracted from the zeolite matrix, however careful control on desilication depth is desired to avoid the formation of extraframework $\mathrm{Al}$, equal to, the loss of active centers for MTP reaction. ${ }^{17,18}$ Thus, selective desilication was adapted to achieve substantial modification on acidity and porosity of zeolites.

Pioneering work by Groen ${ }^{19}$ showed that ZSM-5 with a Si/Al ratio range of 25-50 was optimal for generating a uniform mesoporous structure because higher amount of Al protected $\mathrm{Si}$ from excessive removal resulting in a less mesoporous structure. At higher $\mathrm{Si} / \mathrm{Al}$ ratio, limited protection by less $\mathrm{Al}$ led to excessive Si leaching, thus, larger mesopores and lower product selectivity were obtained, which inevitably deceased shape selectivity effect and amount of framework Al because of severe Si leaching. In most cases, $\mathrm{NaOH}$ has been most usually used base to obtain mesoporous ZSM-5 via post treatment, ${ }^{20}$ however $\mathrm{NaOH}$ has difficulty in control on the desilication depth because of its strong dissolution capability and easy diffusion into channels of zeolites. ${ }^{21}$ Therefore, controllable or protective desilication was designed by incorporating external pore directing agents $\left(\mathrm{Al}(\mathrm{OH})_{4}{ }^{-}, \mathrm{Ga}(\mathrm{OH})_{4}{ }^{-}\right.$, or $\left.\mathrm{TPA}^{+}\right)$or organic amine in the alkaline medium..$^{22,23}$ Framework Al should be preserved as much as possible during $\mathrm{Si}$ extraction to form 
sufficient mesopores. For zeolites in alkaline solution, dissolution (desilication) and crystallization (protection on zeolitic frameworks) are two main reactions occurred, which were influenced by $\mathrm{OH}^{-}$and templating capability. Careful consideration on capability between dissolution $(\mathrm{NaOH})$ and crystallization (protecting agent) should be weighted to achieve better balance. Subsequent ion exchange process is usually needed for these zeolites treated in presence of $\mathrm{NaOH}$ to act as acid catalysts. In this paper, better balance between dissolution of Si and protecting effects on framework might be perfectly achieved by only one agent without $\mathrm{NaOH}$. Bulky quaternary ammonium hydroxide is a favorable choice to satisfy these requirements with $\mathrm{OH}^{-}$(dissolution of $\mathrm{Si}$ ) and quaternary ammonium cation (protection on zeolitic framework), however strong tendency of crystallization toward MFI structure might have reverse effects on the formation of mesopores. Therefore, tetraethylammonium hydroxide (TEAOH), which is larger than micro pore sizes of ZSM-5, was intentionally selected as the post treating reagent to achieve better balance between dissolution and crystallization without addition of $\mathrm{NaOH}$.

This paper presented a protective method to introduce mesopores within highly siliceous H-ZSM-5 by sole TEAOH. Various characterizations were utilized to propose the mechanism on the formation of intracrystalline mesopores within $\mathrm{H}$ ZSM-5 zeolite, and to explain corresponding benefits on lifetime, propylene selectivity, and coke species during MTP reaction over TEAOH-treated H-ZSM-5 catalysts.

\section{Experimental}

\subsection{Preparation}

Commercially available H-ZSM-5 $\left(\mathrm{SiO}_{2} / \mathrm{Al}_{2} \mathrm{O}_{3}=200\right)$ was used as provided by Sinopec Catalyst CO., LTD Changling Division. Pseudo-boehmite were firstly dissolved in the TPAOH solution at $140{ }^{\circ} \mathrm{C}$ for $2 \mathrm{~h}$ to form clear homogenous solution, and then seeds, silica gel, deionized water were mixed to form synthesis gel with batch composition as following: $\mathrm{SiO}_{2}: \mathrm{Al}_{2} \mathrm{O}_{3}:$ TPAOH $: \mathrm{H}_{2} \mathrm{O}=1: 0.005: 0.06: 6$. The synthesis was carried out at $120^{\circ} \mathrm{C}$ for $24 \mathrm{~h}$ with stirring. The product was filtered, washed and dried at $120^{\circ} \mathrm{C}$ overnight. Parent H-ZSM-5 was obtained via calcinations of as-made ZSM-5 for $6 \mathrm{~h}$ in a muffle furnace to remove organics.

Parent H-ZSM-5 was treated in TEAOH solution with typical batch composition in terms of molar ratio as: $\mathrm{TEAOH} / \mathrm{SiO}_{2}=$ $0.04, \mathrm{H}_{2} \mathrm{O} / \mathrm{SiO}_{2}=4$. The post treatment was carried out in a Teflon-lined autoclave at $170{ }^{\circ} \mathrm{C}$ for various time. The product was recovered by filtration, washed and dried in oven at $120^{\circ} \mathrm{C}$ overnight, and calcined at $550{ }^{\circ} \mathrm{C}$ for $4 \mathrm{~h}$. The final obtained samples were designated as parent ZSM- 5 and T- $x$ h, in which T$x \mathrm{~h}$ indicated the ZSM- 5 zeolite treated by TEAOH for different hours. For comparison, TPAOH-treated H-ZSM-5 (labeled as TPA-16 h) was also characterized and subject to MTP reaction.

\subsection{Characterization}

The powder X-ray diffraction (XRD) patterns of different zeolite samples were recorded on an EMPYREAN powder diffractometer (PANalytical Corporation, Netherland) using $\mathrm{Cu}$ $\mathrm{K} \alpha$ radiation $(\lambda=0.154 \mathrm{~nm})$ at a scanning rate of $0.02^{\circ} \mathrm{min}^{-1}$ from $5^{\circ}$ to $35^{\circ}$. The relative crystallinity of the samples were calculated by standard sample in the laboratory. The chemical compositions of the samples were determined on an X-ray fluorescence (XRF) spectrometer ZSX Primus II (Rigaku). X-ray photoelectron spectroscopy data were obtained using an ESCALab 250 electron spectrometer from Thermo Fisher Scientific Corporation with monochromatic $150 \mathrm{~W} \mathrm{AlK} \alpha$ radiation. Pass energy for the narrow scan is $30 \mathrm{eV}$. The base pressure was about $6.5 \times 10^{-10}$ mbar. The binding energies were referenced to the $\mathrm{Cl}_{\mathrm{s}}$ line at $284.8 \mathrm{eV}$ from alkyl or adventitious carbon.

Nitrogen adsorption-desorption isotherms were performed on a Micro-meritics ASAP 2420 instrument. Fresh samples were outgassed under vacuum for $15 \mathrm{~h}$ prior to the adsorption measurements. The Brunauer-Emmett-Teller (BET) equation was used to calculate the surface area. The total pore volumes were evaluated from the volume adsorbed at $p / p_{0}=0.99$, whereas the micropore surface area and the microspore volume were determined by the $t$-plot method.

The morphology of samples was examined by scanning electron microscopy (SEM) on a HITACHI S-4800 microscope. Transmission electron microscopy (TEM) images were recorded on a JEM-2100 transmission electron microscope operating at an accelerating voltage of $200 \mathrm{kV}$.

The ${ }^{27} \mathrm{Al}$ and ${ }^{29} \mathrm{Si}$ magic angle spinning nuclear magnetic resonance (MAS NMR) spectra were recorded on a Bruker Avance III $500 \mathrm{WB}$ spectrometer with the $7 \mathrm{~mm} \mathrm{ZrO}_{2}$ rotor. The frequencies of the ${ }^{27} \mathrm{Al}$ and ${ }^{29} \mathrm{Si}$ MAS NMR were 156.4 and 99.3 MHz, respectively. The ${ }^{27} \mathrm{Al}$ MAS NMR spectrum with the single pulse sampling, pulse width was $0.4 \mu$ s and the revolution of MAS was $12 \mathrm{kHz}$. The ${ }^{29} \mathrm{Si}$ MAS NMR spectrum with the single pulse sampling, pulse width was $2.1 \mu$ s and the revolution of MAS was $5 \mathrm{kHz}$.

$\mathrm{NH}_{3}$-TPD experiments were carried out on an Autochem II 2920 unit equipped with a thermal conductivity detector. $50 \mathrm{mg}$ of zeolite was degassed in a He stream at $600{ }^{\circ} \mathrm{C}$ for $1 \mathrm{~h}$. After cooling to $150{ }^{\circ} \mathrm{C}$, the sample was put in a mixed gas flow of $10 \%$ $\mathrm{NH}_{3}$ and $90 \% \mathrm{He}\left(40 \mathrm{~mL} \mathrm{~min}^{-1}\right)$ for the sufficient adsorption of the $\mathrm{NH}_{3}$. After $30 \mathrm{~min}$, the flow was switched to nitrogen, and TPD profiles were recorded from 150 to $600{ }^{\circ} \mathrm{C}$ at a constant heating rate of $10{ }^{\circ} \mathrm{C} \mathrm{min}^{-1}$ under He flow $\left(40 \mathrm{~mL} \mathrm{~min}{ }^{-1}\right)$. The desorbed ammonia was monitored by a thermal conductivity detector.

The deactivated samples were characterized using a thermal gravimetric analyzer (STA 449 F5, NETZSCH Corporation). In a typical run, about $15 \mathrm{mg}$ of the spent sample was placed in the crucible and heated to $900{ }^{\circ} \mathrm{C}$ in a $60 \mathrm{~mL} \mathrm{~min}{ }^{-1}$ air stream at a heating rate of $10{ }^{\circ} \mathrm{C} \mathrm{min}^{-1}$, while the mass change was recorded.

The soluble coke species were analyzed according to the method described by Guisnet. ${ }^{24}$ Retained hydrocarbons soluble in $\mathrm{CH}_{2} \mathrm{Cl}_{2}$ were extracted by dissolving $20 \mathrm{mg}$ of deactivated catalysts with a given fraction in $1 \mathrm{~mL} 40 \% \mathrm{HF}$ for $3 \mathrm{~h}$. After neutralization $\left(\mathrm{pH}=7\right.$ ) with $2 \mathrm{M} \mathrm{NaOH}$ solution, $6 \mathrm{~mL} \mathrm{CH}_{2} \mathrm{Cl}_{2}$ was added to Teflon beaker to extract the organic compounds 
trapped within deactivated MTP catalysts. Then, organic phase and insoluble coke were separated by separatory funnel. The mixing of organic compounds and insoluble coke were oscillated with ultrasonic for $3 \mathrm{~h}$. Organic compounds were obtained by filtration and concentrated to $0.8-1 \mathrm{~mL}$, and then analyzed by an Agilent 7890 A-5975C equipped with a HP-5 MS column.

\subsection{Catalytic tests}

MTP reaction was carried out in a fixed-bed continuous-flow reactor with a titanium tube of $12 \mathrm{~mm}$ inner diameter and $250 \mathrm{~mm}$ in length. In a typical run, $3 \mathrm{~g}$ zeolite catalyst (20-40 mesh) was located in the flat-temperature zone of the reactor. The mixture of methanol/water (mass ratio $1: 1$ ) was pumped into the reactor by a microtube pump (NS, NP-KX-110) at a methanol WHSV of $4.5 \mathrm{~h}^{-1}$. MTP reaction was conducted at $480{ }^{\circ} \mathrm{C}$ under atmospheric pressure. The gas products were sampled and analyzed by an Agilent-7890A gas chromatograph. Lifetime was defined as TOS from initial time to final time at $90 \%$ conversion. The deactivation rate around $95 \%$ conversion was obtained by linear fitting the data points around $95 \%$.

\section{Results and discussion}

\subsection{Physicochemical properties}

Fig. S1 $\uparrow$ shows the typical powder XRD patterns of the parent, TEAOH-treated H-ZSM-5 and TPA-16 h samples. All samples displayed a characteristic diffraction pattern of MFI topology in ranges of $5-10^{\circ}$ and $22.5-25^{\circ}$ without any competing phase detected. The relative crystallinity first dropped slightly from $88.3 \%$ (parent $\mathrm{H}-\mathrm{ZSM}-5$ ) to $83.5 \%$ at $4 \mathrm{~h}$, and then was further reduced to $82.9 \%$ at $16 \mathrm{~h}$. After $16 \mathrm{~h}$ relative crystallinity was gradually recovered to $85.0 \%$ at $24 \mathrm{~h}$ and $88.1 \%$ at $48 \mathrm{~h}$, respectively. On one hand, $\mathrm{OH}^{-}$of TEAOH could dissolve Si from the framework of parent H-ZSM-5, however bulky TEA ${ }^{+}$hindered free diffusion of $\mathrm{OH}^{-}$throughout parent H-ZSM-5. Therefore, there was a slight decrease of relative crystallinity before $16 \mathrm{~h}$. On the other hand, TEAOH was effective structure directing agent for highly siliceous zeolites besides ZSM-5. ${ }^{25}$ The recrystallization capability of TEAOH toward MFI structure could be proven by the recovery in relative crystallinity at $24 \mathrm{~h}$ and $48 \mathrm{~h}$ with parent $\mathrm{H}$ ZSM-5 as seeds. No formation of amorphous or other new phase emerge was observed in presence of parent H-ZSM-5, which showed superior stability of ZSM-5 via a dissolutionrecrystallization process in TEAOH solution. Moreover, with better recrystallization capability than TEAOH, TPA-16 h showed higher relative crystallinity of $84.5 \%$ than that of $\mathrm{T}-16 \mathrm{~h}$.

Table 1 shows the chemical compositions of calcined samples. During post treatment, $\mathrm{SiO}_{2} / \mathrm{Al}_{2} \mathrm{O}_{3}$ ratio dropped slightly from 197.6 to 193.1 at 16 h, which indicated occurrence of slight desilication. With longer treating time, desilication depth gradually enlarged to decrease $\mathrm{SiO}_{2} / \mathrm{Al}_{2} \mathrm{O}_{3}$ ratio to $176.6(24 \mathrm{~h})$ and 174.8 (48 h), respectively. However, the relative crystallinity was even recovered to $85.0 \%$ and $88.1 \%$ for samples at $24 \mathrm{~h}$ and $48 \mathrm{~h}$. This phenomenon could be explained by the dissolution effects and subsequent recrystallization induced by $\mathrm{OH}^{-}$and $\mathrm{TEA}^{+}$of $\mathrm{TEAOH}$, respectively. These results clearly showed
Table 1 Chemical compositions of parent, TEAOH-treated H-ZSM-5 and TPA-16 $\mathrm{h}$ samples

\begin{tabular}{lcccccc}
\hline Zeolite & H-ZSM-5 & T-4 h & T-16 h & T-24h & T-48 h & TPA-16 h \\
\hline $\mathrm{Na}_{2} \mathrm{O}, \mathrm{w} \%$ & 0.03 & 0.07 & 0.05 & 0.04 & 0.03 & 0.04 \\
$\mathrm{Al}_{2} \mathrm{O}_{3}, \mathrm{w} \%$ & 0.85 & 0.86 & 0.87 & 0.95 & 0.96 & 0.87 \\
$\mathrm{SiO}_{2}, \mathrm{w} \%$ & 98.8 & 98.8 & 98.8 & 98.7 & 98.7 & 98.7 \\
$\left(\mathrm{SiO}_{2} / \mathrm{Al}_{2} \mathrm{O}_{3}\right)$ XRF & 197.6 & 195.3 & 193.1 & 176.6 & 174.8 & 192.9 \\
$\left(\mathrm{SiO}_{2} / \mathrm{Al}_{2} \mathrm{O}_{3}\right)$ XPS & 115.9 & 93.9 & 83.0 & 84.4 & 91.6 & 96.3 \\
\end{tabular}

stronger tendency toward MFI structure of TEAOH with parent $\mathrm{H}^{-}$ ZSM-5 as seeds than desilication effects of $\mathrm{OH}^{-}$in TEAOH, which contributed to the stable crystalline structure of parent H-ZSM-5. More importantly, there was hardly detection of $\mathrm{Al}$ in mother liquor during TEAOH treatment because of suitable alkalinity and protective effects via recrystallization toward MFI structure in presence of H-ZSM-5 seeds. According to the XPS and XRF data, it was clear that parent H-ZSM-5 showed an Al-rich exterior (superficial $\mathrm{SiO}_{2} / \mathrm{Al}_{2} \mathrm{O}_{3}=115.9$ determined by XPS) and Si-rich interior (bulk $\mathrm{SiO}_{2} / \mathrm{Al}_{2} \mathrm{O}_{3}=197.6$ determined by XRF). The reason of discrepancy between bulk (XRF) and surface (XPS) $\mathrm{SiO}_{2} /$ $\mathrm{Al}_{2} \mathrm{O}_{3}$ molar ratios was decided by the synthesis condition of parent H-ZSM-5. Parent H-ZSM-5 was found from a siliceous core to an Al-rich rim, which resulted to higher bulk $\mathrm{SiO}_{2} / \mathrm{Al}_{2} \mathrm{O}_{3}$ than superficial $\mathrm{SiO}_{2} / \mathrm{Al}_{2} \mathrm{O}_{3}$. R. V. Ballmoos first found that $\mathrm{Al}$ concentration in the core was below that in the rim of ZSM-5 zeolite in 1981. Moreover, Al was invariably concentrated in the rim of ZSM-5 crystals. ${ }^{26}$ During TEAOH treatment, superficial $\mathrm{SiO}_{2} / \mathrm{Al}_{2} \mathrm{O}_{3}$ ratio (115.9, parent $\mathrm{H}-\mathrm{ZSM}-5$ ) was decreased to 93.9 (4 h) and $83.0(16 \mathrm{~h})$ because desilication occurred on the surface at first. Although further desilication proved by XRF results, superficial $\mathrm{SiO}_{2} / \mathrm{Al}_{2} \mathrm{O}_{3}$ ratio increased to $84.4(24 \mathrm{~h})$ and 91.6 (48 h) due to severe exposure of Si-rich interior. During TPAOH treatment, TPA-16 h sample showed bulk $\mathrm{SiO}_{2} / \mathrm{Al}_{2} \mathrm{O}_{3}$ of 192.9, similar to that of T-16 h (193.1). However, superficial $\mathrm{SiO}_{2} / \mathrm{Al}_{2} \mathrm{O}_{3}$ ratio of TPA-16 h sample (96.3) was obviously higher than that of T-16 h sample (83.0) which implied that better recrystallization capability of TPAOH transformed more Si species in solution recrystallized into ZSM-5 crystal shell.

During TEAOH treatment on H-ZSM-5, Si species could be selectively removed from the external surface, and then inner of the H-ZSM-5 crystals, which resulted in causing the formation of mesopores ranging in several $\mathrm{nm}$ coupled with a substantial mesopore volume at expense of micropores. Parent H-ZSM-5 possessed a typical I isotherm, indicating microporosity of parent H-ZSM-5. TEAOH-treated H-ZSM-5 samples showed two hysteresis loops in $\mathrm{N}_{2}$ adsorption-desorption isotherms shown in Fig. 1. The first hysteresis loop appearing at $p / p_{0}=0.1-0.4$ was associated with the phenomenon of the fluid-to-crystalline phase transition of adsorbed $\mathrm{N}_{2}$ on the ZSM-5 zeolite with high $\mathrm{Si} / \mathrm{Al}$ ratio, while the second hysteresis loop appearing at $p / p_{0}=$ 0.4-1.0 with larger amount of $\mathrm{N}_{2}$ sorption verified the formation of mesopores (Fig. 1a). The efficiency of TEAOH treatment is clearly manifested by the pronounced hysteresis loop of TEAOH-treated samples, which corresponds to a significant mesopore distribution with an obvious peak at $2-3 \mathrm{~nm}$ in Fig. 1b. With IV type isotherms, the TPA-16 h sample showed 

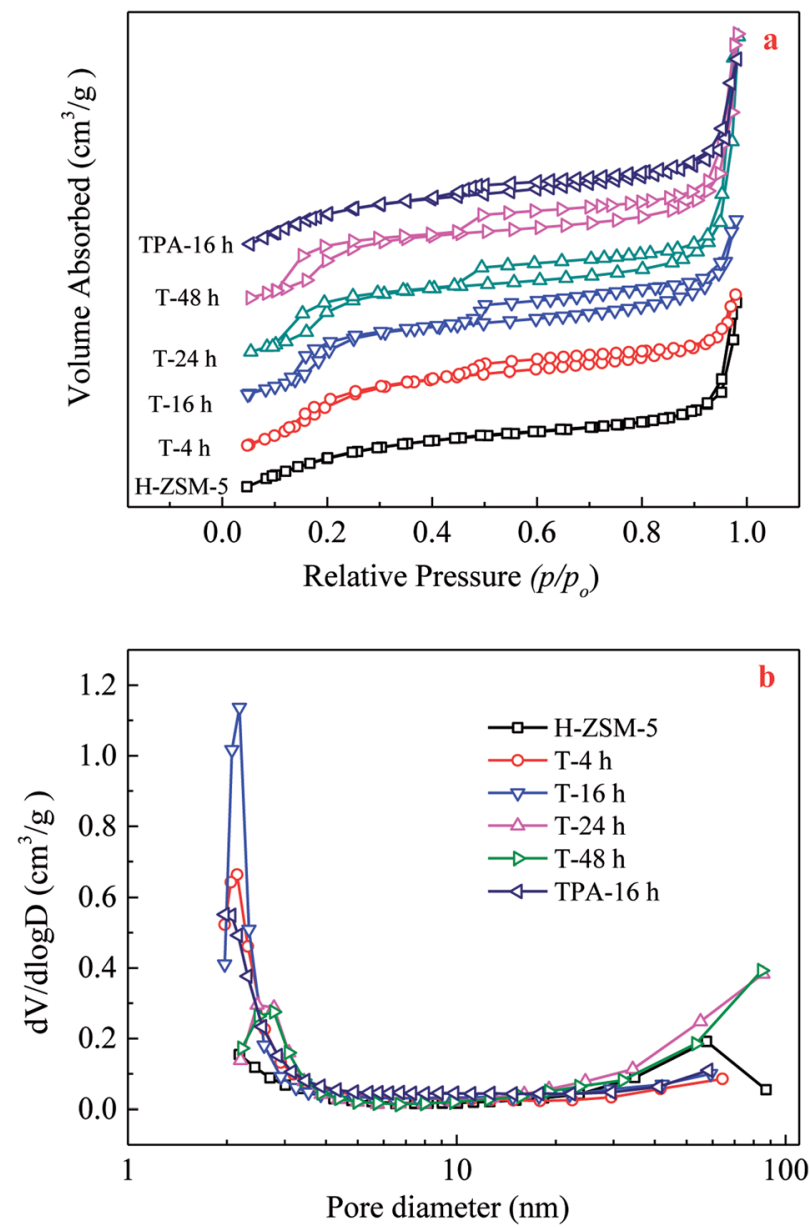

Fig. $1 \mathrm{~N}_{2}$ adsorption-desorption isotherms (a) and BJH adsorption pore-size distribution (b) of the parent, TEAOH-treated $\mathrm{H}-\mathrm{ZSM}-5$ and TPA-16 h samples.

much smaller hysteresis loops and pore distribution than T$16 \mathrm{~h}$. The results about textural properties of parent H-ZSM-5, TEAOH-treated H-ZSM-5 and TPA-16 h samples were listed in Table 2. The BET surface area, micropore and external surface areas of parent H-ZSM-5 were $429 \mathrm{~m}^{2} \mathrm{~g}^{-1}, 399 \mathrm{~m}^{2} \mathrm{~g}^{-1}$ and $30 \mathrm{~m}^{2}$ $\mathrm{g}^{-1}$, respectively. The total, micropore and mesopore volumes were $0.29 \mathrm{~cm}^{3} \mathrm{~g}^{-1}, 0.19 \mathrm{~cm}^{2} \mathrm{~g}^{-1}$ and $0.10 \mathrm{~cm}^{2} \mathrm{~g}^{-1}$, respectively. After TEAOH treatment, the micropore surface area and pore volume obviously decreased, which proved partial destruction of H-ZSM-5 microporous channels by $\mathrm{OH}^{-}$of TEAOH. It seemed that no obvious change in external surface area was observed, however the mesopore volume first increased up to maximum $0.19 \mathrm{~cm}^{3} \mathrm{~g}^{-1}$ at $16 \mathrm{~h}$. The increase in mesopore volumes contributed to the enhancement in total pore volume in spite of slight loss of micropore volume. These changes clearly proved that TEAOH transformed micropores to mesopores because of its alkalinity and larger sizes than channels of H-ZSM-5. More importantly, the desilication depth should be carefully controlled to avoid subsequent decrease of formed mesopores due to breakup of H-ZSM-5 crystals. Moreover, T-16 h had the largest average pore diameter of $3.87 \mathrm{~nm}$ (Table 2). With treating time longer than $16 \mathrm{~h}$, the formed mesopores decreased because of further desilication, meanwhile the relative crystallinity was recovered by recrystallization. By contrast, after TPAOH treatment, mesopore volume $\left(0.130 \mathrm{~cm}^{3} \mathrm{~g}^{-1}\right)$ of TPA$16 \mathrm{~h}$ was much smaller than that of T-16 $\mathrm{h}\left(0.185 \mathrm{~cm}^{3} \mathrm{~g}^{-1}\right)$ because of better recrystallization capability.

SEM and TEM were employed to characterize the evolution of morphology and fine structure of the H-ZSM-5 during TEAOH treatment. As shown in Fig. 2, parent H-ZSM-5 was monodispersed particles with smooth surface in the range from 100 to $300 \mathrm{~nm}$ in diameters. After TEAOH treatment, the surface of H-ZSM-5 particles became rough because of desilication by $\mathrm{OH}^{-}$ of TEAOH. At $24 \mathrm{~h}$ and $48 \mathrm{~h}$, the breakup of ZSM-5 crystals were observed because of further desilication, however the relative crystallinity was well reserved and recovered to $85.0 \%$ and $88.1 \%$ at $24 \mathrm{~h}$ and $48 \mathrm{~h}$, respectively. This also proved the recrystallization effects of TEAOH which could lead to the formation of irregular morphology through the broken crystals. TEM provided clear observation of formed mesopores during TEAOH and TPAOH treatment (Fig. 3). At $4 \mathrm{~h}$, small mesopores could be observed all over the parent H-ZSM-5, while at $16 \mathrm{~h}$ the mesopores became larger than those at $4 \mathrm{~h}$. The enlargement of mesopores could be realized by further dissolution of $\mathrm{Si}$ by $\mathrm{OH}^{-}$ of TEAOH within H-ZSM-5 crystals or merge of several mesopores. Although large amount of mesopores were observed in samples at $4 \mathrm{~h}$ and $16 \mathrm{~h}$, it seemed that ZSM-5 shell is completely preserved, which indicated the formation of intracrystalline mesopores. TPA-16 h sample showed rich but smaller bright spots distributing in the crystals (Fig. 3f). During protective desilication in presence of $\mathrm{NaOH}$ and TPAOH, the intracrystalline mesopores could also be formed, which is

Table 2 Nitrogen physisorption characteristics of parent, TEAOH-treated H-ZSM-5 and TPA-16 h samples

\begin{tabular}{|c|c|c|c|c|c|c|c|}
\hline Samples & \multicolumn{3}{|c|}{ Surface area $\left(\mathrm{m}^{2} \mathrm{~g}^{-1}\right)$} & \multicolumn{3}{|c|}{ Pore volume $\left(\mathrm{cm}^{3} \mathrm{~g}^{-1}\right)$} & $\begin{array}{l}\text { Average pore } \\
\text { diameter }(\mathrm{nm})\end{array}$ \\
\hline $\mathrm{T}-4 \mathrm{~h}$ & 409 & 40 & 368 & 0.292 & 0.179 & 0.113 & 3.61 \\
\hline $\mathrm{T}-16 \mathrm{~h}$ & 364 & 35 & 339 & 0.356 & 0.171 & 0.185 & 3.87 \\
\hline $\mathrm{T}-24 \mathrm{~h}$ & 396 & 32 & 364 & 0.351 & 0.174 & 0.177 & 3.78 \\
\hline
\end{tabular}

${ }^{a}$ BET surface area. ${ }^{b}$ Micropore surface area evaluated by $t$-plot method. ${ }^{c}$ Total pore volume at $p / p_{0}=0.99 .{ }^{d}$ Mesopore volume calculated using $V_{\text {total }}-V_{\text {micro }}$. 

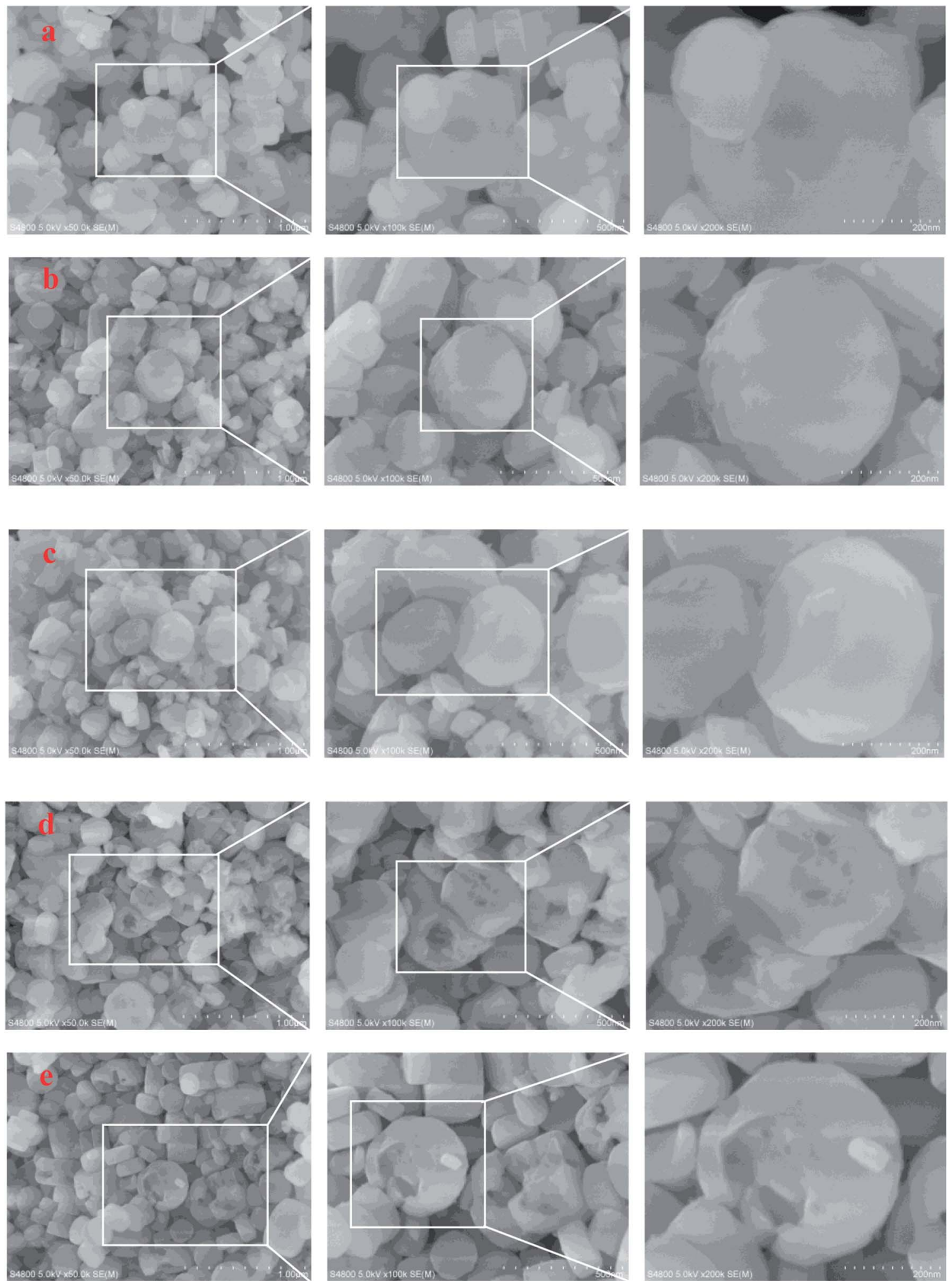

Fig. 2 SEM images of the parent and TEAOH-treated H-ZSM-5 samples ((a) parent H-ZSM-5, (b) T-4 h, (c) T-16 h, (d) T-24 h, (e) T-48 h).

ascribed to the adsorption of $\mathrm{TPA}^{+}$onto the zeolite, sealing off most of the available external surface, hereby largely inhibiting surface realumination, contrary to what occurs in pure $\mathrm{NaOH} .{ }^{27}$ However, our results supported the fact that higher Si concentration near external surface could be easily recrystallized into ZSM-5 shell to cover the formed mesopores. Meanwhile, without enough Si dissolution within crystals was the major reaction to enlarge intracrystalline mesopores. After $16 \mathrm{~h}$, intracrystalline mesopores became even larger which led to the thin shell of ZSM-5. When the shell was too thin to keep its shape, further desilication led to the breakup of ZSM- 5 crystals at $24 \mathrm{~h}$ and $48 \mathrm{~h}$ (Fig. $2 \mathrm{~d}$ and e). 

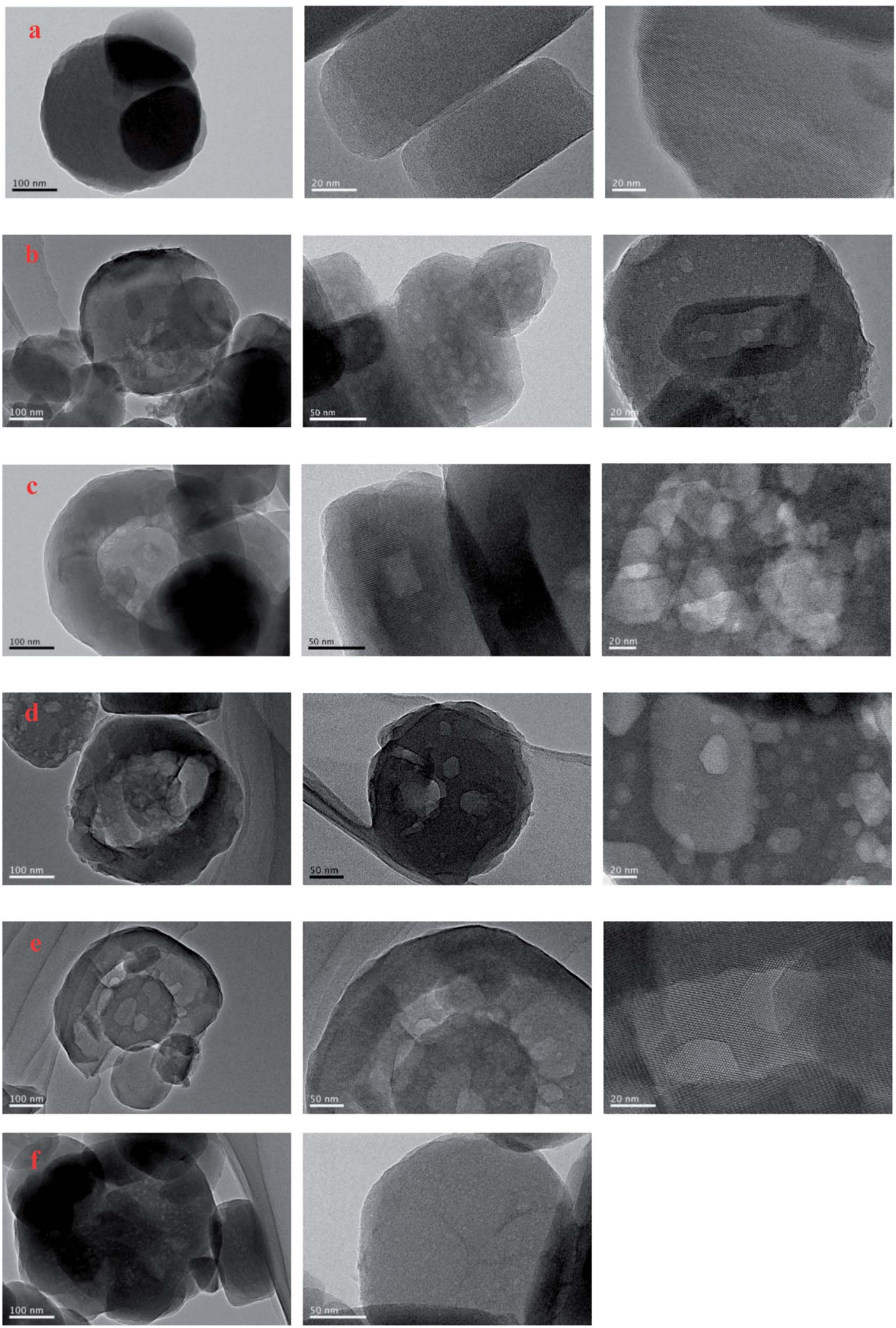

Fig. 3 TEM images of the parent, TEAOH-treated H-ZSM-5 and TPA-16 h samples ((a) parent H-ZSM-5, (b) T-4 h, (c) T-16 h, (d) T-24 h, (e) T$48 \mathrm{~h}$, (f) TEA-16 h).

${ }^{27} \mathrm{Al}$ MAS NMR was conducted to characterize the chemical environment of $\mathrm{Al}$ of zeolites. As shown in Fig. 4a, a single resonance centered at about 55 ppm was clearly observed for all
ZSM-5 samples, which was assigned to four-coordinated framework $\mathrm{Al}$ species. No obvious resonance centered at about $0 \mathrm{ppm}$ assigned to six-coordinated extra-framework $\mathrm{Al}$ 

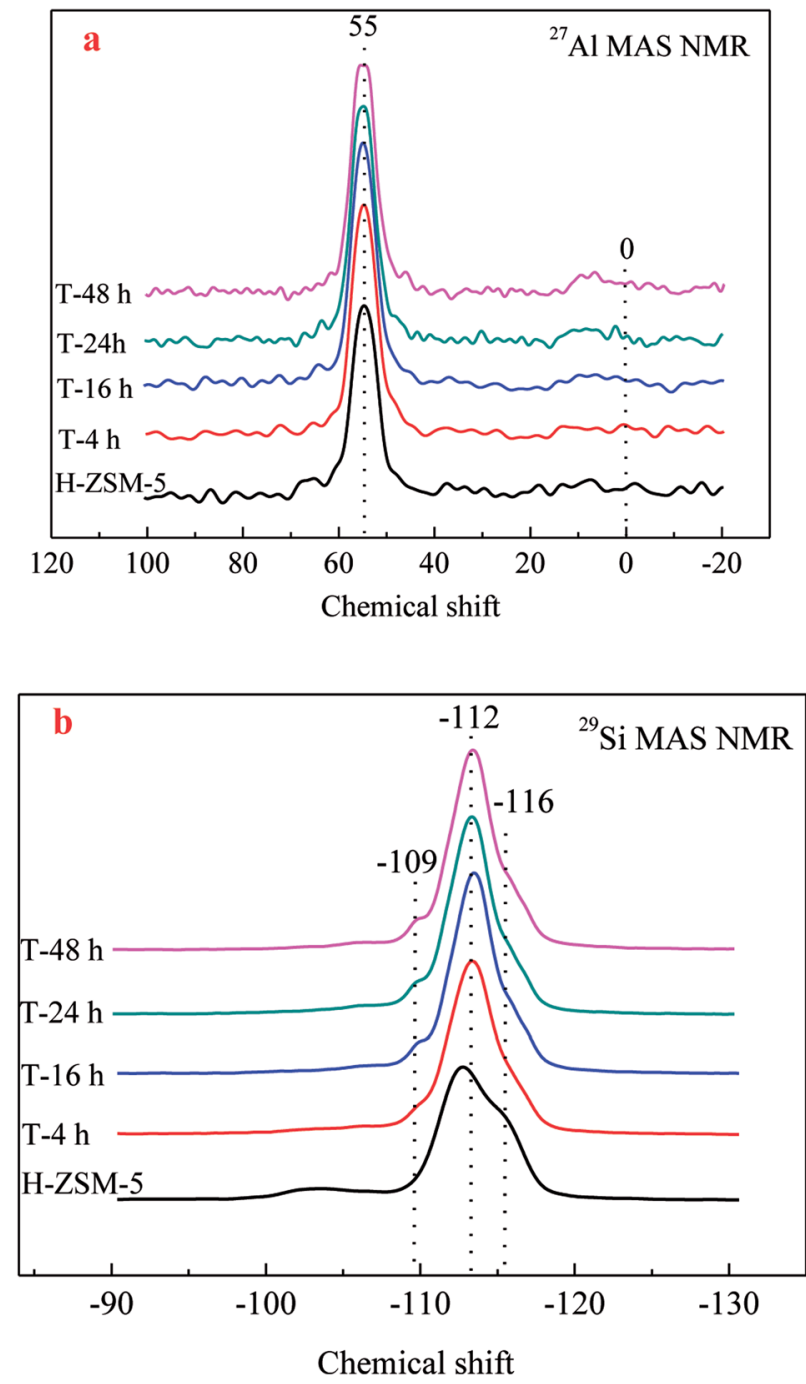

Fig. $4{ }^{27} \mathrm{Al} /{ }^{29} \mathrm{Si}$ MAS NMR spectra of the parent and TEAOH-treated H-ZSM-5 samples ((a) ${ }^{27}$ Al MAS NMR; (b) ${ }^{29}$ Si MAS NMR).

species was observed, which could prove the reservation of framework Al by TEAOH during desilication. Similar results could also be found in the results of ${ }^{29} \mathrm{Si}$ MAS NMR in Fig. 4b. All the ${ }^{29} \mathrm{Si}$ resonances had similar peaks, which could be resolved by deconvolution into three peaks centered at $-109,-112$, and $-116 \mathrm{ppm}$, respectively. Accordingly, the peaks around $-109 \mathrm{ppm}$ corresponded to $\mathrm{Si}(3 \mathrm{Si}, 1 \mathrm{Al})$ sites, while the resonances around -112 and $-116 \mathrm{ppm}$ were assigned to the $\mathrm{Si}(4 \mathrm{Si}$, 0Al) sites. After treatment by TEAOH, the resonance of $\mathrm{Si}(4 \mathrm{Si}$, OAl) sites was slightly decreased indicating the $\mathrm{Si}$ atoms in $\mathrm{Si}$ rich surroundings were easy to be selectively dissolved to form mesopores, which moved the resonances at lower field (far from $\mathrm{Al})$ to higher field. With the loss of $\mathrm{Si}(4 \mathrm{Si}, 0 \mathrm{Al}), \mathrm{Si}(3 \mathrm{Si}, 1 \mathrm{Al})$ became slightly increased.

\subsection{Mechanism on the formation of intracrystalline mesopores}

Based upon above results of characterization, the mechanism of intracrystalline mesopores in presence of TEAOH was illustrated (Fig. 5). There were two different reactions proceeded

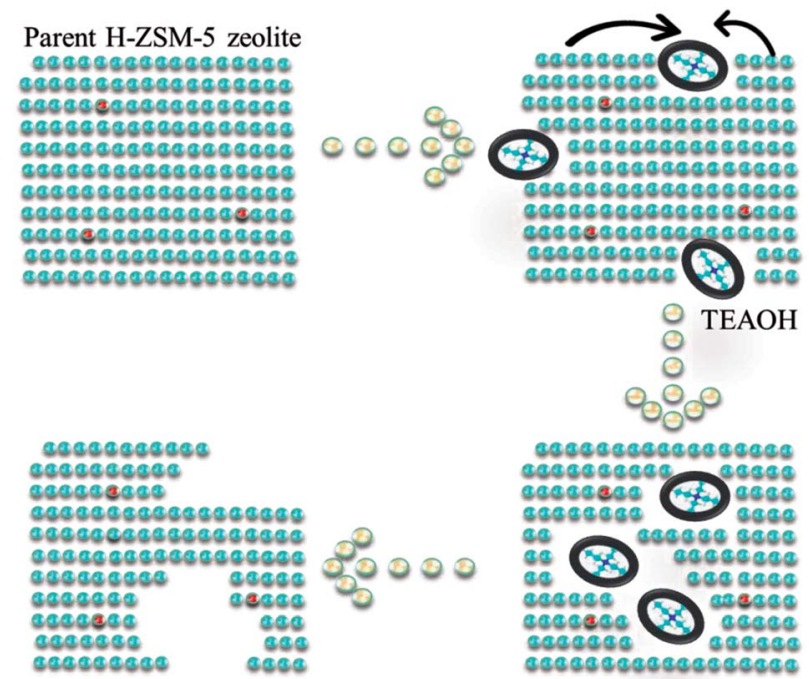

Fig. 5 Mechanism diagram on the formation of intracrystalline mesopores.

when parent H-ZSM-5 was treated by TEAOH solution. The dissolution of framework elements and recrystallization proceeded simultaneously, which showed reverse effects on parent H-ZSM-5 zeolite. Si species was selectively extracted from frameworks in Si rich area by $\mathrm{OH}^{-}$of TEAOH. In general, the dissolution rate and depth mainly depended on the sizes, alkalinity and type of base. As mentioned in literature, ${ }^{21} \mathrm{NaOH}$ was most usually used to generate mesopores of ZSM-5, however easy diffusion of $\mathrm{OH}^{-}$all over the parent zeolites made it difficult to achieve selective desilication of parent zeolites, especially for highly siliceous zeolites. Even worse, framework $\mathrm{Al}$ could be transformed to extra-framework $\mathrm{Al}$ because of severe desilication. Si species were selectively dissolved with better preservation of crystallinity for effective generation of mesopores within parent H-ZSM-5. TEAOH has lower alkalinity and larger sizes than $\mathrm{Na}^{+}$, therefore it has poorer dissolution capability. However, it might have better capability to form larger mesopores because of bulkier sizes of TEAOH molecules. TPAOH has similar structure to TEAOH, however its strong crystallization capability toward ZSM-5 could lead to lower efficiency during the formation of mesopores within parent $\mathrm{H}^{-}$ ZSM-5. For above considerations, TEAOH was selected to be the post treatment agent to generate mesopores within parent H-ZSM-5.

TEAOH which possesses suitable alkalinity and crystallization capability could make the formation of mesopores more effective. At first, $\mathrm{OH}^{-}$simultaneously dissolved Si to destroy micropores via alkalinity, which led to the decrease of micropore surface area and slight loss of crystallinity (4-16 h). The dissolution of $\mathrm{Si}$ led to slight decrease in bulk and superficial $\mathrm{SiO}_{2} / \mathrm{Al}_{2} \mathrm{O}_{3}$ ratio at $4 \mathrm{~h}$ and $16 \mathrm{~h}$. It is well known that sizes of TEAOH were much larger than channels of ZSM-5. Desilication by $\mathrm{OH}^{-}$means the damage on micropores from external surface to inner surface due to diffusion limitation of $\mathrm{TEA}^{+}$. The pore mouth was enlarged by selective dissolution of $\mathrm{Si}$, with enough Si species available on the external surface, ZSM-5 could be 
recrystallized to form a shell, which is the reason for the formation of intracrystalline mesopores. As a result, mesopores were formed within ZSM-5 crystals, in other words the microporous ZSM-5 shell was preserved at suitable treatment time (Fig. 3b). With prolonged treating time, mesopores became larger and larger to form macropores either via simple desilication or merge of mesopores until the ZSM-5 shell broke up. From TEM and SEM images, broken particles via severe desilication could be found obviously. The framework near Al was reserved as shown in Fig. 4a as a result of protection effect of $\mathrm{TEA}^{+}$on $\mathrm{Al}$ or faster recrystallization rate based on higher $\mathrm{Si}$ concentration in mother liquor. A. Galarneau found similar results that the stable mesoporous SBA-15 zeolite could be formed under more severe hydrothermal treatment, or by dissolution/redeposition processes during water treatment. ${ }^{28-30}$

In all, the relative rate of dissolution and recrystallization during TEAOH-treatment on H-ZSM-5 $\left(\mathrm{SiO}_{2} / \mathrm{Al}_{2} \mathrm{O}_{3}=200\right)$ was mainly determined by TEAOH and concentration of active $\mathrm{Si}$ species. Active Si species in mother liquor could be recrystallized to form ZSM-5 shell to cover generated mesopores and finally balanced between formation of mesopores and growth of ZSM-5 crystal. The formed mesopores might benefit the accessibility of acid sites and diffusion of products off the ZSM-5 channels. The diffusivity was improved because the TEAOH treated H-ZSM-5 at suitable time could be regarded as much shorter diffusion channels connected by intracrystalline mesopores.

\subsection{Acidity}

$\mathrm{NH}_{3}$-TPD measurements were carried out to investigate the acidity of the parent and TEAOH-treated H-ZSM-5 samples. As shown in Fig. $\mathrm{S} 2, \dagger$ each of the profile was characterized by two desorption peaks in the $\mathrm{NH}_{3}$-TPD profiles. The low temperature desorption peak (200-240 ${ }^{\circ} \mathrm{C}$ ) corresponded to weak acid sites, while the high temperature peak $\left(330-400{ }^{\circ} \mathrm{C}\right)$ to strong acid sites. The weak and strong acid amounts of the parent and TEAOH-treated H-ZSM-5 samples were listed in Table 3 . Compared with the parent ZSM-5 of $0.198 \mathrm{mmol} \mathrm{g}^{-1}$, the total acidity of T- $4 \mathrm{~h}$ and T-16 h decreased to $0.200 \mathrm{mmol} \mathrm{g}^{-1}$ while T$24 \mathrm{~h}$ and $\mathrm{T}-48 \mathrm{~h}$ increased to 0.220 and $0.205 \mathrm{mmol} \mathrm{g}^{-1}$, respectively. Such enhancement in strong acid sites is accordingly attributed to the increased $\mathrm{Al}$ concentration after desilication (Table 1). Moreover, with longer treating time, the desorption peak of strong acid sites also shifted to higher temperature. As shown in Table 3, T-16 h has fewer strong acid

Table 3 Acid properties of parent and TEAOH-treated H-ZSM-5 samples

\begin{tabular}{llll}
\hline & \multicolumn{2}{l}{ Acidity $/\left(\mathrm{mmol} \mathrm{g}^{-1}\right)$} & \\
\cline { 2 - 4 } Samples & Total acidity & Strong acidity & Weak acidity \\
\hline H-ZSM-5 & 0.198 & 0.021 & 0.183 \\
T-4 h & 0.200 & 0.026 & 0.174 \\
T-16 h & 0.200 & 0.030 & 0.170 \\
T-24 h & 0.220 & 0.022 & 0.198 \\
T-48 h & 0.205 & 0.018 & 0.187
\end{tabular}

sites than parent and TEAOH-treated H-ZSM-5 samples which was expected to improve the catalytic performance in the MTP reaction.

\subsection{Catalytic performance of MTP reaction}

Methanol conversion versus time on stream (TOS) over H-ZSM-5 zeolites was shown in Fig. 6. The lifetime for methanol conversion higher than $90 \%$ varied among the samples. All catalysts showed high initial activity with complete conversion of methanol. For parent H-ZSM-5, methanol was completely converted within $20 \mathrm{~h}$, and then quick deactivation occurred. The activity fell below $90 \%$ after 25 h. In contrast, TEAOH treatment obviously promoted the catalytic longevity. The complete conversion of methanol over TEAOH-treated H-ZSM-5 lasted for $30 \mathrm{~h}$ (T-4 h), $48 \mathrm{~h}(\mathrm{~T}-16 \mathrm{~h}), 36 \mathrm{~h}(\mathrm{~T}-24 \mathrm{~h})$, and $37 \mathrm{~h}(\mathrm{~T}-48$ $\mathrm{h}$ ), while the longevity increased to $106 \mathrm{~h}(\mathrm{~T}-4 \mathrm{~h}), 140 \mathrm{~h}(\mathrm{~T}-16 \mathrm{~h})$, $120 \mathrm{~h}(\mathrm{~T}-24 \mathrm{~h})$, and $96 \mathrm{~h}(\mathrm{~T}-48 \mathrm{~h})$, respectively. With suitable treatment time, $\mathrm{T}-16 \mathrm{~h}$ sample had the longest lifetime. The conversion remained above $99 \%$ for $79 \mathrm{~h}$, and the activity fell below $90 \%$ after $140 \mathrm{~h}$ on stream. The whole lifetime was 5.6 times longer than parent H-ZSM-5. However, the catalyst lifetime of T-24 h and T-48 h was slightly shorter than that of T$16 \mathrm{~h}$, which were $120 \mathrm{~h}$ and $96 \mathrm{~h}$, respectively. TPA-16 h sample possessed the same trend of TOS as the TEAOH-treated samples (Fig. S3 $\dagger$ ). However, the complete conversion of methanol over TPA-16 h sample lasted for $31 \mathrm{~h}$, which was shorter than T-16 h sample of $48 \mathrm{~h}$. Moreover, the catalytic longevity of TPA-16 h sample was $100 \mathrm{~h}$ compared with T-16 h sample of $140 \mathrm{~h}$. The excessive protective effect of $\mathrm{TPA}^{+}$resulted in formation of mesopores, however better recrystallization capability limited the increase in mesopores. Table 4 compares methanol treatment capacity and average propylene selectivity under similar conditions in the literature..$^{31-35}$ Under the condition of $480{ }^{\circ} \mathrm{C}$, $4.5 \mathrm{~h}^{-1}$, the methanol treatment capacity of $\mathrm{T}-16 \mathrm{~h}$ sample was $648 \mathrm{~g}$ methanol per $\mathrm{g}$ catalyst which was superior among results reported in the MTP reaction.

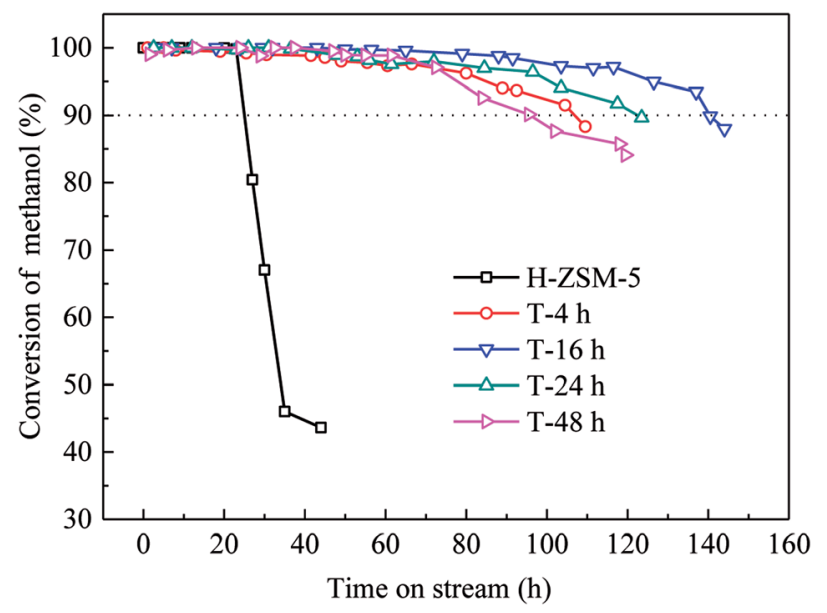

Fig. 6 Variation of methanol conversion with the time-on-stream (TOS) over the parent and TEAOH-treated H-ZSM-5 samples. (Reaction conditions: $T=480{ }^{\circ} \mathrm{C}, \mathrm{WHSV}=4.5 \mathrm{~h}^{-1}, P=0.1 \mathrm{MP}, m\left(\mathrm{H}_{2^{-}}\right.$ O) : $m\left(\mathrm{CH}_{3} \mathrm{OH}\right)=1: 1$ ). 
Table 4 Methanol treatment capacity and average propylene selectivity under similar conditions in the literatures

\begin{tabular}{|c|c|c|c|c|c|}
\hline 480 & 0.9 & 72 & 45.0 & 31 & 2015 \\
\hline 470 & 8 & 304 & 41.1 & 33 & 2017 \\
\hline 480 & 0.9 & 475 & 46.2 & 34 & 2017 \\
\hline 470 & 8 & 712 & 41.9 & 35 & 2018 \\
\hline
\end{tabular}

Different deactivation rates were observed over parent and TEAOH-treated samples. The instantaneous deactivation rate of methanol conversion at 95\% over ZSM-5 catalysts was $4.69 \%$ $\mathrm{h}^{-1}$ (parent H-ZSM-5), $0.21 \% \mathrm{~h}^{-1}$ (T-4 h), $0.18 \% \mathrm{~h}^{-1}$ (T-16 h), $0.22 \% \mathrm{~h}^{-1}(\mathrm{~T}-24 \mathrm{~h})$, and $0.28 \% \mathrm{~h}^{-1}(\mathrm{~T}-48 \mathrm{~h})$, respectively. Nevertheless, all the TEAOH-treated H-ZSM-5 samples showed much slower deactivation rates than parent H-ZSM-5. Obviously, post treatment of H-ZSM-5 by TEAOH was effective to decrease deactivation rates during MTP reaction. More importantly, this method worked in a rather wide range. Even short treatment time could significantly improve the diffusion and catalytic performance of H-ZSM-5 catalysts.

According to results of characterization and proposed mechanism of intracrystalline mesopores formation, mesopores formed within ZSM-5 crystals significantly decreased diffusion length of ZSM-5 channels. The overall TEAOH-treated H-ZSM- 5 could be described as much shorter micro channels of ZSM-5 connected by intracrystalline mesopores. With prolonged treating time, the intracrystalline mesopores became larger either via simple desilication or emerge of adjacent mesopores, which led to the further decrease in diffusion length within micropores but increase in mesopore volumes. With the longer time ( $24 \mathrm{~h}$ and $48 \mathrm{~h}$ ), the broken ZSM-5 crystals led to disappearance of intracrystalline mesopores. With the recovery of relative crystallinity, the micropore channels could be recovered to increase diffusion length. In general, the improvement in lifetime was achieved by significantly decrease length of micropore channels, which were connected by formed intracrystalline mesopores.

Similar to lifetime and deactivation rates of ZSM-5 catalysts, intracrystalline mesopores showed important effects on the coke deposits of deactivated catalysts. In this section, the deactivated samples (parent H-ZSM-5 and T-16 h) were characterized to verify the reason for lifetime improvement. As shown in Fig. 7, the weight loss between $300{ }^{\circ} \mathrm{C}$ and $700{ }^{\circ} \mathrm{C}$ was due to coke burn-off, which could be regarded as total coke content. The deactivated parent H-ZSM-5 has a coke content of around $3.59 \%$, whereas deactivated $\mathrm{T}-16 \mathrm{~h}$ sample showed a higher coke content of $5.27 \%$. The coke content of the deactivated T$16 \mathrm{~h}$ sample was obviously higher than the deactivated parent ZSM-5, however the rate of deactivation of T-16 h sample $(0.18 \%$ $\left.\mathrm{h}^{-1}\right)$ was much slower than parent H-ZSM-5 $\left(4.69 \% \mathrm{~h}^{-1}\right)$. The higher content was due to better capacity for coke deposits in mesopores, the mesopore volumes of which was $0.185 \mathrm{~cm}^{3} \mathrm{~g}^{-1}$, much larger than $0.104 \mathrm{~cm}^{3} \mathrm{~g}^{-1}$ of parent H-ZSM-5. Moreover, the better capacity for coke deposits of $\mathrm{T}-16 \mathrm{~h}$ sample might explain the longer lifetime of T-16 h sample. It is also reported previously $^{36,37}$ that the coke content of mesoporous zeolite was higher than parent zeolite, because of mesopore formation for more coke deposit holding. Generally, higher coke content means serious deactivation, however, T-16 h sample showed much slower deactivation rate than parent H-ZSM-5 because of much shorter diffusion length due to intracrystalline mesopores. Not only T-16 h sample showed a higher coke content than parent H-ZSM-5 zeolite, but also the soluble carbonaceous residuals were different. Fig. 8 shows the GC-MS for the retained species of deactivated parent H-ZSM-5 and T-16 h samples. Aromatic molecules such as xylenes, trimethylbenzenes and tetramethyl benzenes were detected within these two samples. For the deactivated parent H-ZSM-5, the content of xylenes, trimethylbenzenes and tetramethyl benzenes was $43.9 \%$, $26.3 \%$, and $7.0 \%$, respectively. By contrast, the situation was quite different for deactivated T-16 h sample with intracrystalline mesopores. The content of xylenes of the deactivated T-16 h decreased to $31.4 \%$, while tetramethyl benzenes rose to $11.3 \%$. Moreover, there existed a small peak of pentamethyl benzenes reaching to $1.0 \%$, which supported the formation of heavier compounds in deactivated $\mathrm{T}-16 \mathrm{~h}$ sample. The $\mathrm{T}-16 \mathrm{~h}$ sample had larger space, which had the chance to accommodate polymethyl benzenes. Interestingly, K. Góra-Marek et al. ${ }^{\mathbf{3 8}}$ also found that the desilication procedure could lead to catalyst modifications which allow larger molecules to be formed within the zeolite crystals. The presence of larger aromatic molecules over desilicated sample was straightforwardly associated with improved lifetime because of larger mesopores. With formation

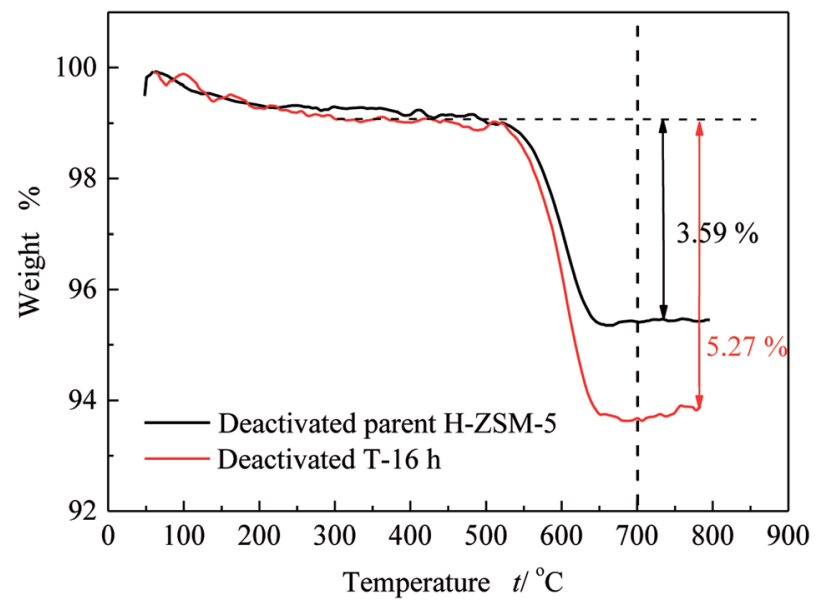

Fig. 7 TG results of deactivated parent $\mathrm{H}-\mathrm{ZSM}-5$ and $\mathrm{T}-16 \mathrm{~h}$ samples. 


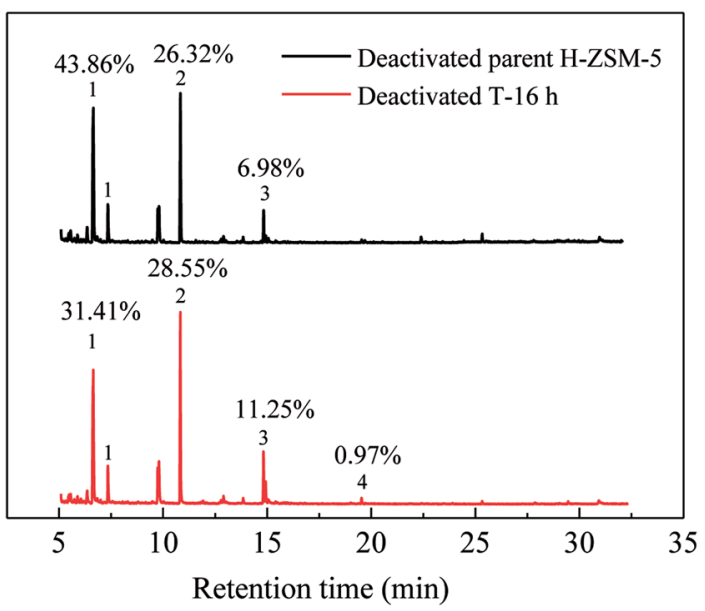

Fig. 8 GC-MS analyses of retained hydrocarbons of deactivated parent $\mathrm{H}-\mathrm{ZSM}-5$ and $\mathrm{T}-16 \mathrm{~h}$ samples. Chromatograms from the dissolution-extraction experiments for deactivated samples. (1) Xylenes, (2) trimethylbenzenes, (3) tetramethyl benzenes, (4) pentamethyl benzenes.

of intracrystalline mesopores, also much shorter diffusion length contributed to slower deactivation rate.

The propylene selectivity, $\mathrm{P} / \mathrm{E}$ ratio $\left(\mathrm{C}_{3}=\mathrm{C}_{2}=S_{\text {propylene }} /\right.$ $\left.S_{\text {ethylene }}\right)$ and $\mathrm{C}_{3}$ hydrogen transfer index $\left(\mathrm{C}_{3}-\mathrm{HTI}, S_{\text {propane }} /\right.$

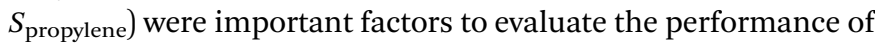
catalyst. Propylene selectivity, $\mathrm{C}_{3}=\mathrm{C}_{2}^{\overline{ }}$ and $\mathrm{C}_{3}$-HTI of the parent and TEAOH-treated H-ZSM-5 samples versus TOS are shown in Fig. 9. As seen from Fig. 9a, when methanol was completely converted from initial time to $24 \mathrm{~h}$, the propylene selectivity of parent H-ZSM-5 sample varied between $32.6 \%$ and $34.5 \%$, and then decreased sharply along TOS because of fast deactivation. Ethylene selectivity decreased from $11.2 \%$ to $9.6 \%$, which resulted in higher P/E ratio from 2.9 to 3.6 (Fig. $9 \mathrm{~b}$ and e). Parent H-ZSM-5 showed the highest methane selectivity as it grew from $0.9 \%$ to $2.9 \%$ during the whole lifetime (Fig. $9 \mathrm{~d}$ ). $\mathrm{C}_{3}$ hydrogen transfer index $\left(\mathrm{C}_{3}-\mathrm{HTI}\right)$ is a convenient assessment of the hydrogen transfer activity of a catalyst, and often used to evaluate the extent of secondary reaction in MTH reaction. Obviously, the parent H-ZSM-5 zeolite had the highest initial $\mathrm{C}_{3}$-HTI of 0.047 (Fig. 9f), which indicated secondary reaction of propylene was extremely high. By contrast, the TEAOH-treated H-ZSM-5 samples with mesoporosity were prominent for their higher propylene selectivity and lower methane selectivity. When TOS increased, the TEAOH-treated samples showed little change in propylene selectivity, decreasing ethylene selectivity, and increasing methane selectivity. Propylene selectivity of T$4 \mathrm{~h}$ varied between $34.5 \%$ and $37.8 \%$. Ethylene selectivity decreased from $7.7 \%$ to $5.7 \%$, meanwhile methane selectivity increased from $0.1 \%$ to $0.5 \%$. The trends of propylene and ethylene selectivity resulted in the higher $\mathrm{P} / \mathrm{E}$ ratio from 4.8 to 6.1 (Fig. 9e). T-16 h, T-24 h and T-48 h samples had higher propylene and much lower methane selectivity (below 0.3\%) than T-4 h sample. Moreover, the T-16 h sample with the largest mesopores volume also showed lowest methane selectivity (below 0.3\%) (Fig. 9d), and the lowest initial $\mathrm{C}_{3}$-HTI of 0.027 (Fig. 9f) presumably due to the shortened diffusion lengths. By contrast, the TPA-16 h sample (Fig. S4 $\dagger$ ) with rich but smaller mesopores volume showed propylene selectivity decreased slightly from $39.5 \%$ to $35.6 \%$, meanwhile ethylene selectivity decreased from $9.5 \%$ to $5.3 \%$. The trends of propylene and ethylene selectivity resulted in $\mathrm{P} / \mathrm{E}$ ratio changed from 4.1 to 6.8 . Moreover, TPA-16 h sample also had higher methane selectivity (from $0.3 \%$ to $0.8 \%$ ) and initial $\mathrm{C}_{3}$-HTI of 0.034 due to the different diffusion performance compared with T-16 h sample.

Recently, "dual cycle" mechanism proposed in pioneering work provided a good explanation to the formation of ethylene and propylene, which showed two reaction cycles running synchronously in the methanol-to-hydrocarbon process: an aromatic-based alkylation-dealkylation cycle and an olefinbased methylation-cracking cycle. ${ }^{39,40}$ The scheme of dualcycle concept is summarized in Fig. 10, propylene and ethylene could be generated by the aromatic-based cycle, whereas $\mathrm{C}_{2}^{+}$olefins mainly propylene was produced by the olefin-based cycle without formation of ethylene. The dual cycle mechanism was rather a closely connected two circles with mutual influence than simple paralleling reactions. The olefins generated in the aromatic-based cycle were active intermediates for olefin-based cycles, while higher alkenes formed in olefinsbased cycles could be transformed into aromatics via dimerization, cyclization and dehydrogenation. As for post treatment of H-ZSM- 5 by TEAOH, the main difference lied in the diffusion properties of catalyst. It has been extensively proved that better diffusion properties and shorter contact time could restrict alkylation-dealkylation reactions, which led to lower ethylene selectivity ${ }^{41,42}$ It is also well documented in the literature that reduction of crystal sizes could shorten the resident time of aromatics which would restrict the aromatic-based alkylationdealkylation cycle, thus led to much lower ethylene selectivity. ${ }^{43}$ R. Khare $e t$ al. also found that self-pillared ZSM-5 with higher diffusion performance showed lower ethylene selectivity. ${ }^{4}$ Thus, methods for improving diffusion performance such as reduction of crystal sizes and creation of mesopores were considered effective to enhance mass transfer and to improve catalytic performance. Introduction of intracrystalline mesopores into H-ZSM-5 remarkably decreased the length of channels with more opening mouth, which could significantly promote the diffusion of reactant/product into/off to acid sites for longer lifetime and better propylene selectivity. More importantly, the micro pores could be gradually blocked because of coke deposition. Olefins and aromatics were active intermediates for the olefin-based and the aromatic-based cycles respectively, which differed in concentrations, sizes, reaction activity and so on. In general, more olefins with much higher activity than aromatics were generated during MTP reaction, more importantly as active intermediates olefins in the olefin-based cycle needed much smaller space for the methylation-cracking route than aromatic in the aromaticbased cycle for the alkylation-dealkylation. The free space size within zeolite channels gradually decreased along TOS, which had fewer restricting effects on olefin-based cycle. However, space restriction was more influential to the aromatic-based cycle, which led to the gradual decrease in ethylene selectivity. With further blocking of channels of H-ZSM-5, there was no 

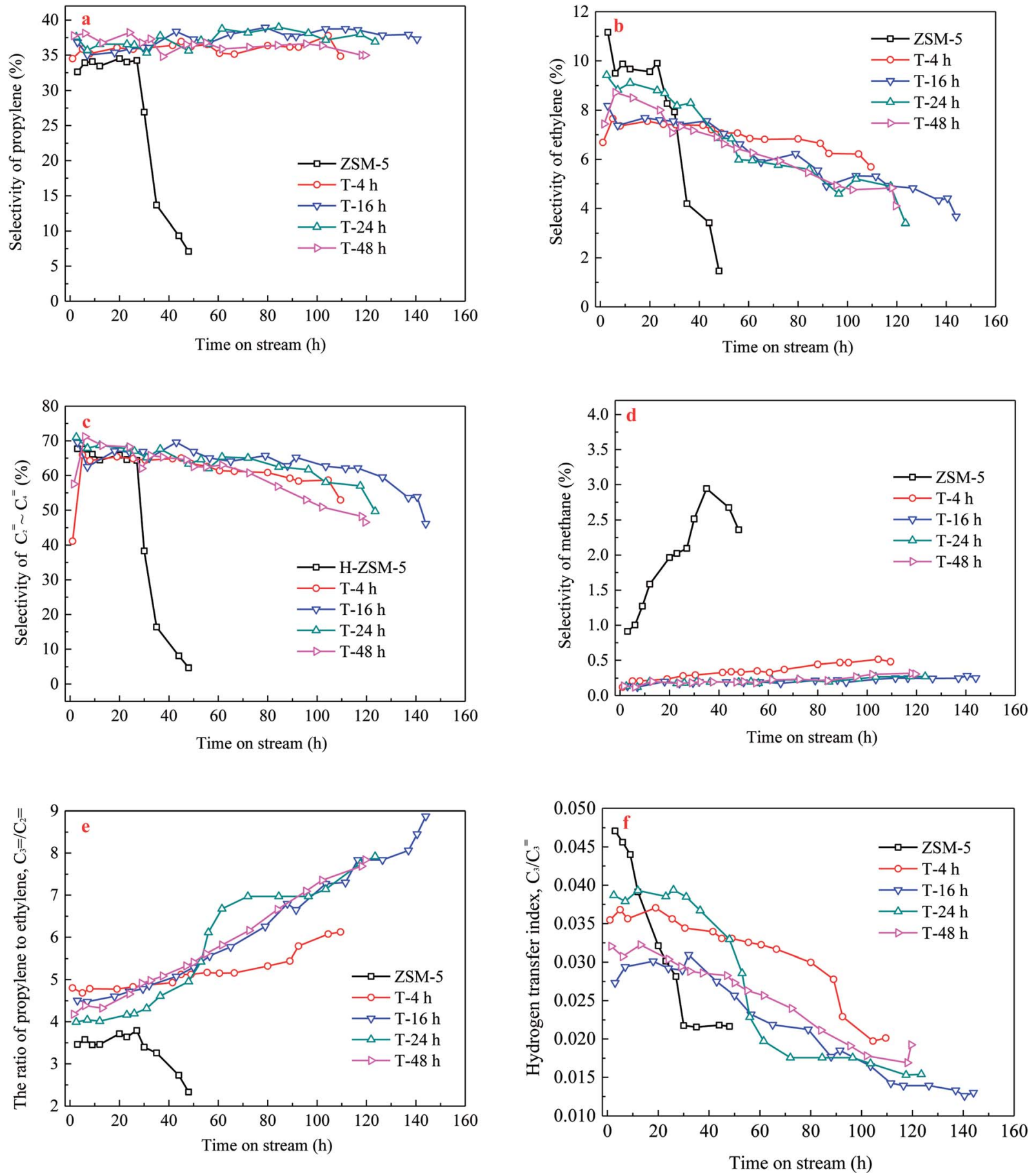

Fig. 9 Product selectivity ((a) propylene, (b) ethylene, (c) $C_{2}=C_{4},(d)$ methane), $C_{3} / C_{2}=(e)$ and $C_{3}$ hydrogen transfer index (f) of the parent and TEAOH-treated H-ZSM-5 samples for MTP reaction as a function of time. Reaction conditions: $T=480{ }^{\circ} \mathrm{C}, \mathrm{WHSV}=4.5 \mathrm{~h}-1, P=0.1 \mathrm{MP}$, $m\left(\mathrm{H}_{2} \mathrm{O}\right): m\left(\mathrm{CH}_{3} \mathrm{OH}\right)=1: 1$.

enough free space for the formation of transitional states of methylation of aromatics, which resulted in a decrease in methanol conversion. More importantly, methylation-cracking in the olefin-based cycle could also be decreased with severe blockage of channels.

It was proposed that methane was formed via reduction of a methyl group by hydride transfer ${ }^{39}$ and decomposition of methanol. On one hand, methanol could dehydrate to form dimethyl ether on acid sites and was further converted to hydrocarbons. On the other hand, methanol decomposition occurred simultaneously. Parent H-ZSM-5 sample had an especially high methane selectivity, which might be related to the poor diffusion. Poor accessibility of acid site means methanol decomposition a certain probability occurs. However, the TEAOH-treated samples showed much lower amount of methane compared to parent H-ZSM-5 sample. This may be ascribed to the hollow structure, introducing a mesoporous structure improved the accessibility of acid site which could 


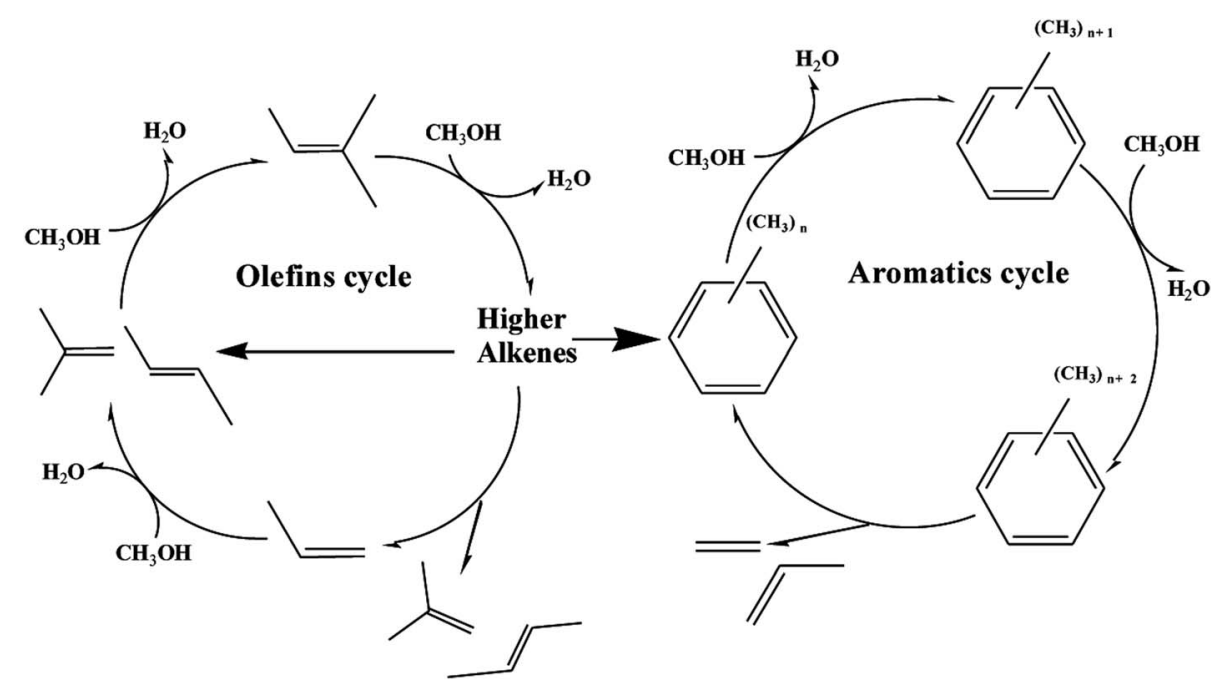

Fig. 10 Scheme of dual-cycle concept (olefins cycle and aromatics cycle) during MTP reaction over H-ZSM-5 zeolite.

suppress the content of methanol decomposition. Thus, methanol decomposition occurred at a much slower rate than methanol conversion to olefins which results to much lower methane selectivity. Moreover, the methane selectivity of parent H-ZSM-5 and TEAOH-treated samples both increased along TOS. This may be ascribed to the decreasing of acidity due to coke deposition.

In all, the diffusion length of H-ZSM-5 could be remarkably decreased by intracrystalline mesopores in zeolite via protective desilication in $\mathrm{TEAOH}$, which could significantly enhance lifetime, product selectivity and coke tolerance with much lower methane selectivity and deactivation rates.

\section{Conclusions}

In summary, this study presented a protective method to introduce intracrystalline mesopores within highly siliceous $\mathrm{H}$ ZSM-5 by TEAOH treatment, during which there were two different reactions: dissolution of $\mathrm{Si}$ by $\mathrm{OH}^{-}$and recrystallization of dissolved Si into ZSM-5 by TEA ${ }^{+}$in presence of seeds. At first, the external crystal $\mathrm{Si}$ was selectively dissolved to form mesopores at cost of micropores, and then active Si species in mother liquor could be recrystallized to form ZSM-5 shell to cover generated intracrystalline mesopores. With prolonged treating time, intracrystalline mesopores became larger and larger either via simple desilication or merge of adjacent mesopores. With intracrystalline mesopores, original channels of parent H-ZSM-5 was cut into much shorter ones by formed mesopores. The formed mesopores within ZSM-5 was broken from inner via further desilication to restore relative crystallinity and micropore surface.

Because of much shorter diffusion length, the TEAOHtreated H-ZSM-5 samples were demonstrated to be an excellent MTP catalyst with longer lifetime and higher propylene selectivity. A good correlation between the mesoporosity and the catalytic longevity was found. Lifetime and high propylene selectivity have a closely relationship with pore structure. T-16 h sample, with the largest mesopore volumes, exhibited the longest lifetime (140 h) and higher propylene selectivity (36.6\%) relative to the parent H-ZSM-5 sample.

This method proved a simple method for intracrystalline mesopore formation with better balance between dissolution $\left(\mathrm{OH}^{-}\right)$and recrystallization $\left(\mathrm{TEA}^{+}\right)$in TEAOH only for better design on MTP catalyst with high stability and propylene selectivity.

\section{Conflicts of interest}

There are no conflicts to declare.

\section{Acknowledgements}

Careful characterization of samples from the Department of Analysis in Research Institute of Petroleum Processing, Sinopec was greatly acknowledged.

\section{Notes and references}

1 M. Firoozi, M. Baghalha and M. Asadi, Catal. Commun., 2009, 10, 1582-1585.

2 A. Muntasar, R. L. V. Mao and H. Yan, Ind. Eng. Chem. Res., 2010, 49, 3611-3616.

3 C. Sun, J. M. Du, J. Liu, Y. Yang, N. Ren, W. Shen, H. L. Xu and Y. Tang, Chem. Commun., 2010, 46, 2671-2673.

4 P. Tian, Y. Wei, M. Ye and Z. Liu, ACS Catal., 2015, 5, 19221938.

5 S. Hu, J. Shan, Q. Zhang, Y. Wang, Y. Liu, Y. Gong and T. Dou, Appl. Catal., A, 2012, 445, 215-220.

6 B. Jiang, F. Xiang, L. Yan, Y. Jiang, Z. Liao, J. Wang and Y. Yang, Ind. Eng. Chem. Res., 2014, 53, 4623-4632.

7 X. Meng, Q. Yu, Y. Gao, Q. Zhang, C. Li and Q. Cui, Catal. Commun., 2015, 61, 67-71.

8 J. Wang, Y. Wei, J. Li, S. Xu, W. Zhang, Y. He, J. Chen, M. Zhang, A. Zheng, F. Deng, X. Guo and Z. Liu, Catal. Sci. Technol., 2016, 6, 89-97. 
9 Z. Liu, X. Dong, Y. Zhu, A. H. Emwas, D. Zhang, Q. Tian and Y. Han, ACS Catal., 2015, 5, 5837-5845.

10 S. Ilias and A. Bhan, ACS Catal., 2012, 3, 18-31.

11 G. T. Kokotailo, S. L. Lawton, D. H. Olson and W. M. Meier, Nature, 1978, 272, 437-438.

12 H. Koempel and W. Liebner, Stud. Surf. Sci. Catal., 2007, 167, 261-267.

13 M. Khanmohammadi, S. Amani, A. B. Garmarudi and A. Niaei, Chin. J. Catal., 2016, 37, 325-339.

14 K. Barbera, F. Bonino, S. Bordiga, T. V. W. Janssens and P. Beato, J. Catal., 2011, 280, 196-205.

15 S. Al-Khattaf, C. D'Agostino, M. N. Akhtar, N. Al-Yassir, N. Y. Tan and L. F. Gladden, Catal. Sci. Technol., 2014, 4, 1017-1027.

16 C. Dai, A. Zhang, L. Li, K. Hou, F. Ding, J. Li, D. Mu, C. Song, M. Liu and X. Guo, Chem. Mater., 2013, 25, 4197-4205.

17 S. Abello, A. Bonilla and J. Perez-Ramirez, Appl. Catal., A, 2009, 364, 191-198.

18 D. Verboekend and J. Pérez-Ramírez, Catal. Sci. Technol., 2011, 1, 879-890.

19 J. C. Groen, L. A. A. Peffer, J. A. Moulijn and J. Pérezramírez, Microporous Mesoporous Mater., 2004, 69, 29-34.

20 J. Ahmadpour and M. Taghizadeh, C. R. Chim., 2015, 18, 834-847.

21 M. Bjørgen, F. Joensen, M. S. Holm, U. Olsbye, K. Lillerud and S. Svelle, Appl. Catal., A, 2008, 345, 43-50.

22 H. Liu, S. Xie, W. Xin, S. Liu and L. Xu, Catal. Sci. Technol., 2016, 6, 1328-1342.

23 D. Wang, L. Zhang, L. Chen, H. Wu and P. Wu, J. Mater. Chem. A, 2014, 3, 3511-3521.

24 P. Magnoux, P. Roger, C. Canaff, V. Fouche, N. S. Gnep and M. Guisnet, Stud. Surf. Sci. Catal., 1987, 34, 317-330.

25 P. R. H. P Rao and M. Matsukata, Chem. Commun., 1996, 12, 1441-1442.

26 R. V. Ballmoos and W. M. Meier, Nature, 1981, 289, 782-783.

27 D. Verboekend, G. Vile and J. Pérez-Ramírez, Cryst. Growth Des., 2012, 12, 3123-3132.
28 A. Galarneau, M. Nader, F. Guenneau, F. D. Renzo and A. Gedeon, J. Phys. Chem. C, 2007, 111, 8268-8277.

29 A. Galarneau, H. Cambon, F. D. Renzo and F. Fajula, Langmuir, 2001, 17, 8328-8335.

30 A. Galarneau, H. Cambon, F. D. Renzo, R. Ryoo, M. Choi and F. Fajula, New J. Chem., 2003, 27, 73-79.

31 M. Rostamizadeh and A. Taeb, Synth. React. Inorg. Met.-Org. Chem., 2016, 46, 665-671.

32 H. Chen, Y. Wang, F. Meng, C. Sun, H. Li, Z. Wang, F. Gao, X. Wang and S. Wang, Microporous Mesoporous Mater., 2017, 244, 301-309.

33 H. Chen, Y. Wang, C. Sun, F. Gao, L. Sun, C. Wang, Z. Wang and X. Wang, Catal. Commun., 2017, 100, 107-111.

34 M. Rahmani and M. Taghizadeh, React. Kinet., Mech. Catal., 2017, 122, 409-432.

35 H. Li, Y. Wang, C. Fan, C. Sun, X. Wang, C. Wang, X. Zhang and S. Wang, Appl. Catal., A, 2018, 551, 34-48.

36 Z. Wan, G. Li, C. Wang, H. Yang and D. Zhang, Appl. Catal., A, 2017, 549, 141-151.

37 F. L. Bleken, K. Barbera, F. Bonino, U. Olsbye, K. P. Lillerud, S. Bordiga, P. Beato, T. V. W. Janssens and S. Svelle, J. Catal., 2013, 307, 62-73.

38 K. Sadowska, K. Góra-Marek, M. Drozdek, P. Kuśtrowski, J. Datka, J. M. Triguero and F. Rey, Microporous Mesoporous Mater., 2013, 168, 195-205.

39 X. Sun, S. Mueller, Y. Liu, H. Shi, G. L. Haller, M. SanchezSanchez, A. C. V. Veen and J. A. Lercher, J. Catal., 2014, 317, 185-197.

40 J. Li, M. Liu, X. Guo, S. Xu, Y. Wei, Z. Liu and C. Song, ACS Appl. Mater. Interfaces, 2017, 9, 26096-26106.

41 R. Khare, D. Millar and A. Bhan, J. Catal., 2015, 321, 23-31. 42 M. Zhang, S. Xu, Y. Wei, J. Li, J. Wang, W. Zhang, S. Gao and Z. Liu, Chin. J. Catal., 2016, 37, 1413-1422.

43 N. L. Michels, S. Mitchell and J. Perez-Ramirez, ACS Catal., 2014, 4, 2409-2417.

44 R. Khare and A. Bhan, J. Catal., 2015, 329, 218-228. 